\title{
Actos de habla en redes sociales: perfiles privados versus perfiles públicos*
}

\author{
Speech acts in social networks: private profiles \\ versus public profiles
}

Susana Ridao Rodrigo **

\section{RESUMEN}

El objetivo del presente artículo presentar un análisis de los tipos de actos de habla utilizados en la red social Facebook, con la finalidad de contrastar los datos obtenidos en un corpus de perfiles privados y en un corpus de perfiles públicos. Para ello, se analizó, desde la perspectiva cuantitativa y cualitativa, un corpus compuesto por 1.341 comentarios. Como principales conclusiones destacan: (1) el mayor empleo de actos de habla asertivos, directivos y expresivos; en el corpus I está compensado el uso de estos tres actos de habla, frente al corpus II donde hay mayor frecuencia de los actos asertivos; (2) la baja utilización de actos comisivos; (3) la inexistencia de actos declarativos.

\begin{abstract}
The aim of this paper is to analyze the types of speech acts used in the social network Facebook, in order to contrast the data obtained in a corpus of private profiles and in a corpus of public profiles. For this, a corpus composed of 1341 comments is analyzed from the quantitative and qualitative perspective. The main conclusions are: (1) the greater use of assertive, directive and expressive speech acts; in corpus I the use of these three speech acts is compensated, as opposed to corpus II where there are more assertive acts; (2) the low use of commissive acts; (3) the absence of declaratory acts.
\end{abstract}

Palabras clave: actos de habla, discurso mediado por ordenador, pragmática, redes sociales.

Keywords: computer mediated speech, pragmatics, social networks, speech acts.

Este artículo nace al amparo del grupo de investigación HUM783, el cual está vinculado al centro de investigación CEMyRI de la UAL.

** Española. Doctora en Filología Hispánica por la Universidad de Almería. Profesora titular de la Universidad de Almería. Almería, España. sridao@ual.es 


\section{Introducción}

La utilización generalizada de la tecnología ha revolucionado las formas tradicionales de comunicación entre los individuos. La expansión de internet no solo implica que el usuario tenga a su disposición un maremágnum de información a través de la pantalla de su dispositivo electrónico — como ocurría con la llamada web 1.0—, sino que en la actualidad la web 2.0 ha evolucionado para permitir la retroalimentación entre usuarios, de manera que el sujeto no es un mero receptor, sino que puede ejercer un papel más activo como productor de mensajes que aparecen en la red. Ya en los albores del siglo XXI, Crystal (2001) vaticinó que el ámbito de la lingüística asumiría un relevante papel en internet. Como indica Penas (2018), "Vivimos en un momento histórico donde la transmisión rápida y eficaz de la información es fundamental". Son muchas las publicaciones que han tomado como punto de análisis este contexto comunicativo, con la denominación comunicación mediada por ordenador (CMO) (Pano, 2008), que más adelante se ha preferido llamar discurso mediado por ordenador (DMO), entendiendo por tal "el conjunto de modalidades de interacción que surge de la aplicación de las nuevas tecnologías a la comunicación pública e interpersonal" (Pano y Moya, 2016, p. 2).

Algunos de los estudios pioneros en español abordaron los géneros de los chats y el correo electrónico, como es el caso de Mayans i Planells (2000), Blanco Rodríguez (2002), García Gabaldón (2003), Rocha Silva (2004) o López Alonso (2006), por citar ejemplos de una nómina abismalmente extensa. Más adelante, la proliferación de las redes sociales ha influido en el panorama investigador. De esta forma, en los últimos años buena parte de los trabajos en torno al discurso mediado por ordenador se ha centrado en analizar las redes sociales, contextos donde conviven la comunicación presencial y la virtual (Yus, 2010). Galán y Garlito (2019) entienden que en un sentido amplio una red social "es una estructura social formada por personas o entidades que mantienen, intercambian o fomentan intereses comunes, actividades o vínculos de diversa índole a través de Internet" (p. 15). Precisamente la pragmática ha sido el enfoque adoptado por algunas investigaciones, y más en particular en el estudio de la imagen y, por extensión, de las estrategias de (des)cortesía, si bien es cierto que el panorama anglosajón es mucho más fecundo y temprano, frente a la bibliografía existente en español. Vivas (2016) sostiene 
que las indagaciones que se han efectuado en el ámbito hispánico sobre redes sociales conforman dos polos temáticos: en un extremo, el análisis de los actos de habla valorizadores o halagadores de la imagen positiva del destinatario y, en el otro extremo, las estrategias de descortesía. Estos contextos comunicativos propician no solo las relaciones corteses, sino que también permiten al lingüista analizar corpus donde la descortesía hace acto de presencia.

En esta investigación se ofrece un sucinto repaso del nacimiento y la evolución de la teoría de los actos de habla, vertebrado por los trabajos de Austin (1962) y Searle (1969; 1975). Del mismo modo, se tienen en cuenta las aportaciones sobre actos de habla que efectúa la obra de la Real Academia Española, RAE-Asociación de Academias de la Lengua Española, ASALE (2009). Para el análisis ofrecido en este artículo se han utilizado dos corpus: el primero recopilado de perfiles privados y el segundo de perfiles públicos. Dicho análisis se ha sustentado en la clasificación establecida por Searle (1969) acerca de los actos de habla: asertivos, directivos, comisivos, expresivos y declarativos. Se ha recurrido al estudio de la dimensión cuantitativa y cualitativa, con miras a confrontar los datos hallados. Se cierra este trabajo contrastando las conclusiones obtenidas en otros estudios con intereses compartidos.

\section{Los actos de habla}

Esta teoría goza de una trascendencia incuestionable al ser considerada el germen de la pragmática lingüística, dado que ha logrado modificar el devenir de los estudios de lingüística desde que irrumpió a mediados del siglo XX de la mano de filósofos del lenguaje, en tanto que "a partir de procesos lógicos observan el proceso de elaboración e interpretación de los enunciados en función de las condiciones contextuales" (Pérez García, 2014, pp. 174-175). Según Escandell (2006), la aparición de estos postulados supone un punto de inflexión en el desarrollo de los estudios referidos a la filosofía del lenguaje, como consecuencia de que los enunciados no descriptivos se han abierto un espacio en el ámbito filosófico. La influencia de esta teoría igualmente afectó al psicoanálisis, la antropología, la sociología o la filosofía (Cuamba Herrejón, 2014). En el ámbito lingüístico, sobre todo en la década de los setenta y los ochenta, este legado ha sido tomado como modelo no solo para ser aplicado a diferentes idiomas, sino también en 
la enseñanza de lenguas extranjeras e incluso en la explicación de las interacciones interculturales (Placencia y Bravo, 2002). Se ha de tener en cuenta que existe una limitación a la hora de utilizar la taxonomía de los actos de habla, porque ha sido a partir de la lengua inglesa desde donde se han desarrollado las investigaciones filosóficas con un punto de vista analítico (Ainciburu, 2018).

En concreto, Austin (1962) demuestra que el lenguaje no posee una función meramente descriptiva - tal como se concebía desde la civilización griega-, sino que observa que a través del lenguaje se pueden llevar a cabo acciones; esto es, le otorga un importante papel activo. A estos casos decide denominarlos realizativos. Además, distinguió entre:

- Actos de habla locutivos: aquellos que son estudiados por la filosofía clásica en tanto que se ocupan de la significación literal, dado que expresan algo con sentido y con referencia.

- Actos de habla ilocutivos: aquellos con los que el emisor transmite su intención comunicativa, como es el caso de pedir disculpas o realizar una petición.

- Actos de habla perlocutivos: aquellos que para poder ejecutarse el receptor debe actuar - lo que conlleva que la responsabilidad también recae sobre el alocutario-, siendo acciones como persuadir o convencer.

El trabajo de Calvo (1994) recopila críticas recibidas por esta teoría en cuanto al excesivo protagonismo que otorga Austin (1962) al receptor en los actos de habla perlocutivos, si bien el propio Calvo insiste en que ahí reside la majestuosidad de este principio.

Ciertamente, en los actos de habla resulta relevante lo ilocutivo, dejando a un lado lo locutivo y lo perlocutivo, puesto que los actos de habla se centran en la intención del emisor respecto de qué va a decir y, por supuesto, cómo lo va a cifrar (Giraldo y Londoño, 2017). Austin (1962) se percata de que "what we need is a list of illocutionary forces ${ }^{1}$ of an utterance" (pp. 148-149); he aquí la taxonomía propuesta:

1. Actos judicativos: indican un veredicto sobre el valor de un hecho.

$1 \quad$ En cursiva en el original. 
2. Actos ejercitativos: se acotan al ejercicio de potestades, derechos o influencia.

3. Actos compromisorios: se limitan a prometer o comprometer. Guardan relación con los actos judicativos y los ejercitativos.

4. Actos comportativos: abordan las actitudes y el comportamiento social, formando un grupo bastante heterogéneo.

5. Actos expositivos: son difíciles de definir, pues atienden a la forma en que se están utilizando las palabras, o sea, a la manera en que las expresiones encajan en un argumento, como es el caso de contestar, ejemplificar o suponer.

Por su parte, Searle (1969; 1975) perfecciona el legado respecto de la teoría de los actos de habla que había dejado su maestro Austin (1962). El propio Searle (1969) reconoce explícitamente que su obra no es un ensayo sobre lingüística: “The speech act or acts performed in the utterance of a sentence are in general a function of the meaning of the sentence" (p. 18). Aparte, sostiene que los actos de habla son unidades de comunicación lingüística cifrados según reglas. Distingue entre actos de habla directos e indirectos en función de si hay correspondencia entre significado literal e intención comunicativa, de manera que en los actos de habla indirectos el receptor primero piensa en el acto literal y en segundo lugar recapacita acerca de la intención comunicativa del emisor (Searle, 1975). Señala Garrido Medina (1999) que el empleo de actos de habla indirectos posibilita salvaguardar la imagen social tanto del hablante como del receptor, de forma que aminora la descortesía que poseen por naturaleza determinados actos de habla directos.

En Searle (1969) se establece una taxonomía con cinco tipos de actos de habla que difiere parcialmente de la defendida por su maestro Austin (1962). A la par, no se trata de categorías excluyentes, sino que en un mismo acto de habla pueden darse varias, porque en el lenguaje real pueden usarse actos de habla híbridos (Verschueren, 2002):

- Actos asertivos: se basan en la verdad o la falsedad, por lo que aluden a acciones como afirmar, anunciar o predecir.

- Actos directivos: el emisor intenta influir en el comportamiento del receptor, tal es el caso de ordenar, preguntar, pedir o recomendar. 
- Actos comisivos: el hablante adquiere un compromiso al pronunciar el acto de habla, con acciones como prometer, ofrecer o jurar.

- Actos expresivos: el actor transmite subjetividad, sentimientos o puntos de vista, siendo ejemplos de esta tipología pedir perdón, felicitar o agradecer.

- Actos declarativos: mediante estos se transforman las ideas del estado de las cosas, de manera que refieren a actos como sentenciar, bautizar o declarar la guerra.

En la obra de la RAE-ASALE (2009) se hace eco tímidamente de la teoría de los actos de habla, relacionándola con la modalidad y con las construcciones imperativas, interrogativas y exclamativas. De esta forma tan didáctica explica qué es un acto de habla:

Los enunciados lingüísticos no solo expresan informaciones, sino que pueden también constituir acciones cuando se usan en las circunstancias comunicativas y sociales adecuadas. En efecto, quien dice Te felicito; Muchas gracias; ¡Cuidado! o ;Cállate! en las condiciones apropiadas no describe un estado de cosas, sino que, por el mismo hecho de usar esas palabras, felicita a su interlocutor, le agradece algo, le hace una advertencia o le da una orden, es decir, lleva a cabo ACTOS VERBALES ${ }^{2}$ o ACTOS DE HABLA (p. 793).

Unas páginas más adelante, advierte que no se ha de pensar que existe una indisociable relación entre acto de habla y modalidad, dado que aunque la modalidad interrogativa se utilice principalmente para hacer preguntas, también puede usarse para formular una petición (iMe enseña su pasaporte?), una negación velada (iTengo yo la culpa de que estuviera cerrado?), una propuesta ( $\dot{Y}$ Y si fuéramos al cine?) o una recriminación (¿Por qué no te tranquilizas?), entre otros (RAE-ASALE, 2009).

\section{Corpus y método}

Se ha de comenzar este epígrafe informando que la recopilación de un corpus extraído de redes sociales no es una tarea tan sencilla como se puede pensar en un primer momento. Sin ir más lejos, Mancera y Pano (2014) reflexionan acerca de los problemas metodológi-

2 En versalitas en el original. 
cos existentes a la hora de recopilar textos de internet, resaltando la representatividad, la información sobre el contexto que resulta necesaria para comprender correctamente el mensaje y, por supuesto, la ética derivada de la privacidad para que el usuario mantenga su anonimato. En el caso de los perfiles privados, se ha de tener en cuenta -además- que esta red social ofrece la posibilidad de establecer políticas de privacidad para que el usuario pueda elegir quiénes ven la información que ha incorporado, lo que evidentemente implica limitaciones a la hora de recopilar el corpus. Otra dificultad propia de los perfiles públicos alude a cuestiones informáticas, en tanto que con relativa frecuencia el número de comentarios incorporados en una publicación a veces es tan elevado que resulta imposible consultarlos todos.

El corpus analizado en esta modesta investigación está disponible en Vivas (2016); en particular, en el presente artículo se van a someter a estudio los corpus I y II de la citada tesis doctoral. Ambos están extraídos de la red social Facebook; la diferencia existente entre ellos reside en que el corpus I recopila publicaciones de perfiles privados, mientras que el corpus II publicaciones de perfiles públicos. El primer corpus contiene 159 publicaciones que alcanzan los 867 comentarios escritos entre los años 2009 y 2013 de veinte usuarios de la red social Facebook - diez hombres y diez mujeres- con edad comprendida entre los 25 y los 35 años, nacionalidad española y estudios universitarios. En cambio, el corpus II está recopilado cronológicamente entre 2012 y 2014 de cuatro perfiles oficiales de personajes públicos - dos hombres y dos mujeres-; en concreto, de Paula Echevarría, Dani Mateo, Jordi Cruz y Samantha Vallejo-Nájera, los cuales tienen en común ser personas muy conocidas en España por su aparición en televisión y en redes sociales. Se ha seleccionado una publicación por cada usuario público - esto es, cuatro publicaciones en total- dado que el número de comentarios obtenido en cada publicación es bastante elevado; de hecho, en total los comentarios hallados en las cuatro publicaciones son 474 . Estos dos corpus suman 1.341 comentarios.

Respecto de la metodología empleada, se somete a estudio el corpus seleccionado en función de las cinco tipologías de actos de habla establecidas por Searle (1969), clasificación que también ha sido utili- 
zada en estudios gramaticales tan consagrados como Garrido Medina (1999). En este trabajo se analiza la doble vertiente del corpus, o sea, la dimensión cuantitativa y la cualitativa, con la intención de facilitar tanto la frecuencia de uso como los fragmentos que los ejemplifican. Otra variable relevante para esta investigación es contrastar los actos de habla que se observan en perfiles privados frente a perfiles públicos. En lo concerniente a cuestiones metodológicas, Blas Arroyo (2014, p. 19) observa que en buena parte de las indagaciones referidas al estudio cualitativo de las interacciones donde hay muestras de descortesía las intuiciones del investigador asumen un indiscutible protagonismo a la hora de analizar tales corpus. Precisamente sobre esta cuestión Kaul y Cordisco (2014) reflexionan acerca de la evaluación que se efectúa sobre los actos de habla considerados descorteses, en cuyo proceso el analista ha de abordar al mismo tiempo tanto el objeto de análisis como el objeto de consulta y comprobación.

\section{Análisis y resultados}

En este apartado primero se facilitan los datos cuantitativos para, a continuación, analizar datos cualitativos. Así pues, en la siguiente tabla se aportan los tipos de actos de habla existentes en los veinte usuarios de Facebook examinados, esto es, en el corpus I. Como se puede observar, los actos de habla asertivos son los más frecuentes (282), seguidos de los actos expresivos (281) y los actos directivos (278), mientras que sin identificar se encuentran 21 comentarios, existen 5 casos de actos comisivos y no hay ningún ejemplo de acto declarativo. Se ha de aclarar que los 21 comentarios que no se han podido identificar responden a textos cuyo significado ha resultado imposible descifrar; tal es el caso de estos comentarios: ".., "uahhh" o “\#locker". Los porcentajes de distribución con clímax de orden descendente son: 32,52\% en actos asertivos, $32,41 \%$ en actos expresivos, $32,06 \%$ en actos directivos, $2,42 \%$ en casos no identificados, $0,57 \%$ en actos comisivos y $0 \%$ en actos declarativos. 
Tabla 1

Distribución de los actos de habla del corpus I

\begin{tabular}{|c|c|c|c|c|c|c|}
\hline & Asertivos & Directivos & Comisivos & Expresivos & Declarativos & $\begin{array}{c}\text { Sin } \\
\text { identificar }\end{array}$ \\
\hline U1 & 6 & 14 & - & 29 & - & \\
\hline $\mathrm{U} 2$ & 15 & 16 & - & 6 & - & 3 \\
\hline U3 & 5 & 9 & - & 16 & - & \\
\hline $\mathrm{U} 4$ & 17 & 31 & 2 & 10 & - & \\
\hline U5 & 12 & 10 & 1 & 18 & - & \\
\hline U6 & 22 & 17 & - & 8 & - & 1 \\
\hline $\mathrm{U} 7$ & 9 & 15 & - & 12 & - & 1 \\
\hline U8 & 8 & 6 & - & 15 & - & \\
\hline U9 & 26 & 21 & - & 3 & - & 2 \\
\hline U10 & 10 & 19 & - & 23 & - & \\
\hline U11 & 21 & 18 & - & 50 & - & 2 \\
\hline U12 & 12 & 18 & - & 13 & - & 2 \\
\hline U13 & 7 & - & - & 12 & - & \\
\hline U14 & 28 & 16 & - & 18 & - & 2 \\
\hline U15 & 1 & 5 & - & 10 & - & \\
\hline U16 & 10 & 21 & 1 & 10 & - & 1 \\
\hline U17 & 30 & 10 & - & 4 & - & \\
\hline U18 & 20 & 12 & 1 & 6 & - & 7 \\
\hline U19 & 13 & 9 & - & 8 & - & \\
\hline U20 & 10 & 11 & - & 10 & - & \\
\hline $\begin{array}{c}\text { Total } \\
\text { frecuencia } \\
\text { absoluta }\end{array}$ & 282 & 278 & 5 & 281 & - & 21 \\
\hline $\begin{array}{l}\text { Total } \\
\text { frecuencia } \\
\text { porcentual }\end{array}$ & $32,52 \%$ & $32,06 \%$ & $0,57 \%$ & $32,41 \%$ & $0 \%$ & $2,42 \%$ \\
\hline
\end{tabular}

Fuente: Elaboración propia.

Por su parte, los resultados correspondientes al corpus II evidencian una marcada predilección por los actos de habla asertivos (299), frente a un menor empleo de actos directivos (94) y actos expresivos (72); con cifras muy bajas están: los casos sin identificar (7), los actos comisivos (2), y los actos declarativos, de los que no se ha hallado ningún comentario de esta naturaleza. Estos datos estadísticamente representan en actos asertivos el 63,08\%, en actos directivos el 19,83\%, en actos expresivos el $15,18 \%$, en casos sin identificar el $1,47 \%$ y en actos declarativos el $0 \%$. 
Tabla 2

Distribución de los actos de habla del corpus II

\begin{tabular}{ccccccc}
\hline & Asertivos & Directivos & Comisivos & Expresivos & Declarativos & Sin identificar \\
\hline P1 & 104 & 57 & - & 16 & - & - \\
\hline P2 & 31 & 22 & 2 & 11 & - & 3 \\
\hline P4 & 149 & 9 & - & 11 & - & 2 \\
\hline $\begin{array}{c}\text { Total } \\
\text { frecuencia } \\
\text { absoluta }\end{array}$ & 15 & 6 & - & 34 & 72 & - \\
\hline $\begin{array}{c}\text { Total } \\
\text { frecuencia } \\
\text { porcentual }\end{array}$ & $63,08 \%$ & $19,83 \%$ & $0,42 \%$ & $15,18 \%$ & $0 \%$ & $1,47 \%$ \\
\hline
\end{tabular}

Fuente: Elaboración propia.

Respecto del análisis cualitativo, se van a aportar ejemplos de los actos de habla usados tanto en el corpus I como en el corpus II. Las redes sociales cada vez más son utilizadas como medio para dar a conocer determinada información, como se demuestra con la elevada cifra de actos asertivos hallados en el presente análisis. De esta manera, en los siguientes comentarios se aprecian casos de actos de habla asertivos, en los cuales los usuarios afirman o anuncian algo:

[1] ¡Trabajo fin de máster terminado! [Corpus I, perfil 6, publicación 6 , comentario 1]

[2] Síí, son d Zara, 99.95 eur nueva colección, solo están en rojo d momento, a mí no me gustan tampoco [Corpus II, perfil 1, publicación 1, comentario 29]

Por supuesto, las redes sociales conforman un espacio proclive para la utilización de actos de habla directivos, como son preguntar, ordenar o pedir. $\mathrm{Si}$, por un lado, a priori se puede creer que esta tipología discursiva no es frecuente en las interacciones verbales por resultar descortés, por el otro, se observa que el contexto en que es emitido puede atenuar parte de esta acción intrínsecamente descortés, además de que en los corpus examinados se ha demostrado numéricamente que se trata de un acto de habla frecuente por parte de los usuarios:

[3] ¿hablamos? Ya he leído qué tal las opos, así que no te pregunto.

Dime si hay un día en que podamos charlar un rato para llamarnos 
a los fijos. Ya de vernos, ni pregunto, ¿verdad? [Corpus I, perfil 4, publicación 5 , comentario 1]

[4] si no lo ves para qué entras a comentar aquí? Qué falta de respeto [Corpus II, perfil 3, publicación 1, comentario 168]

Tal como se indicaba en el análisis cuantitativo, son escasos los comentarios sometidos a estudio en los que el usuario promete, ofrece o jura algo - o sea, los denominados actos comisivos-, como consecuencia de que las redes sociales no resultan contextos propicios para este tipo de acciones. No obstante, se aportan estos ejemplos:

[5] Si de mí dependiera, ya tendrías el sobresaliente cum laude :) [Corpus I, perfil 5, publicación 2, comentario 3]

[6] Si quieres te firmo yo a ti el tuyo! ;P [Corpus II, perfil 2, publicación 1, comentario 18]

Los actos de habla expresivos son muy comunes en los intercambios comunicativos que tienen lugar a través de las redes sociales, si bien es cierto que se aprecian más casos de felicitaciones y de agradecimientos que de peticiones de perdón; he aquí estos comentarios:

[7] Feliz cumpleaños, artista!!! Ya sabes, te deseo todas esas cosas que te desean siempre pero que solo se dicen en un día. Un abrazo y mucha poesía!!! [Corpus I, perfil 11, publicación 2, comentario 24]

[8] Los tres sois geniales. Felicidades [Corpus II, perfil 4, publicación 1, comentario 16]

\section{Discusión y conclusiones}

Como se puede comprobar en el epígrafe precedente, en los datos hallados en los corpus I y II se observan tanto similitudes como diferencias. Como denominador común, en ambos corpus no se cataloga ningún ejemplo de actos de habla declarativos. Asimismo, presentan unos porcentajes similares en comentarios sin identificar (en el corpus I: $2,42 \%$ y en el corpus II: $1,47 \%$ ) y en la frecuencia de uso de los actos comisivos (en el corpus I: $0,57 \%$ y en el corpus II: $0,42 \%$ ). Las diferencias radican en las categorías que emplean con mayor frecuencia. De esta forma, los actos asertivos en el corpus I representan el 32,52\%, mientras que en el corpus II el 63,08\%. En contraposición, en el corpus I hay un $32,06 \%$ de actos directivos, frente al $19,83 \%$ del corpus II. A la 
par, los actos expresivos son más frecuentes en el corpus I (32,41\%) que en el corpus II (15,18\%). En consecuencia, en ambos los actos de habla más frecuentes son los asertivos, los directivos y los expresivos, si bien en el corpus I su distribución es más equitativa, en comparación con el II, donde hay una marcada tendencia a la utilización de actos asertivos frente a un menor empleo de actos directivos y, por último, de actos expresivos. En la Figura 1 se muestra de manera visual esta información:

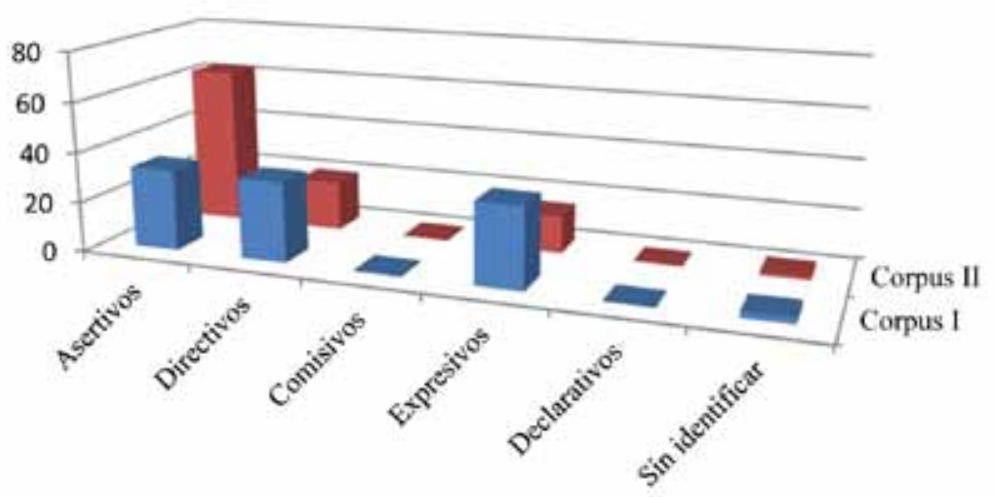

Figura 1. Comparación de los datos sobre actos de habla de los corpus I y II Fuente: Elaboración propia.

A propósito del análisis de este corpus - cuya naturaleza está marcada por la comunicación digital propia de las redes sociales- conviene asumir que, como recuerdan Giraldo y Londoño (2017), cuando un hablante emite un acto de habla pone su foco de atención en lo que quiere decir, y, por extensión, en cómo va a cifrar su mensaje. Precisamente sobre la conversación tecnológica del chat, Sanmartín (2007) dilucida que en el ciframiento de los intercambios comunicativos en el género del chat se han de tener en consideración: los rasgos situacionales relacionados tanto con el contexto como con los participantes, los rasgos concernientes al medio del discurso y a su planificación, los rasgos discursivos propios de los emisores y los rasgos textuales. Los corpus aquí examinados presentan unas características comunicativas muy concretas, dado que han sido extraídos de la red social Facebook. A su vez, la existencia de recursos icónicos y audiovisuales ha adquirido más relevancia desde su incorporación en los contextos digitales, pudiéndose entender que conforman una importante ayuda a la hora 
tanto de potenciar como de estimular las relaciones en las interacciones comunicativas (Berlanga y Martínez, 2010).

En realidad, los usuarios con perfiles privados de la red social Facebook tienen como objetivo la manutención o el establecimiento de las relaciones sociales; esto es, que la función social reemplaza a la función informativa (Vivas, 2016). Existen investigaciones que indagan en la cortesía existente en las redes sociales, en concreto en felicitaciones (Theodoropoulou, 2015), cumplidos (Maíz Arévalo, 2013), cumplidos, halagos y manifestaciones de acuerdo (Mancera y Pano, 2013) o la cortesía valorizadora en general (Vivas, 2014), entre otros. No obstante, también en las redes sociales frecuentemente se encuentran comentarios donde impera la descortesía.

Mientras que en la cortesía las intenciones se descargan por medio de emociones positivas como cordialidad, simpatía, interés, gratitud; en la descortesía, las intenciones vehiculizan emociones negativas que provocan una vulneración en el sistema de valores vigente en la sociedad (Kaul, 2017, p. 20).

Para dar explicación al discurso descortés que - se insiste- con tan elevada asiduidad hace acto de presencia en perfiles públicos, Fuentes (2009) señala que puede deberse al anonimato, a la falta de sinceridad o incluso a la carencia de relación personal. Por su parte, Malamuth et al. (2005) apoyan la teoría de que el anonimato sustenta este tipo de comportamientos incívicos. Según Díaz Pérez (2012), podría justificarse por: el distanciamiento espacial entre los usuarios, la velocidad y la facilidad con la que se codifican estos mensajes o la carencia de normas y, por ende, desinhibición al tratar cuestiones groseras y agresivas. Sobre esta cuestión, entienden Kaul y Cordisco (2014) que se ha procedido a una naturalización de la descortesía como consecuencia de que la comunicación en línea se rige por unas normas diferentes a la comunicación en presencia. Ante este panorama, algunos estudios han abordado la descortesía existente en las redes sociales, como Mak y Chui (2014), Díaz Pérez (2012), Mancera y Pano (2013), Kaul y Cordisco (2014) o Vivas y Ridao (2015), por citar solo algunos ejemplos.

Con un interés investigador común al presente artículo, conviene aludir a dos trabajos que abordan los actos de habla en contextos 
digitales. Así pues, Maíz Arévalo y García-Gómez (2013) analizan los actos de habla con el objetivo de profundizar en el empleo de cumplidos destinados a la evaluación de los otros participantes, así como igualmente se interesa por la forma en que se fortalecen las relaciones sociales; el corpus ha sido recopilado tanto en lengua española como en lengua inglesa. En esta misma línea de estudiar actos de habla en contextos digitales se sitúa Hernández Toribio y Mariottini (2016), si bien el corpus no ha sido extraído de redes sociales, sino de las opiniones de los usuarios de la página en línea de una empresa encargada de ofertar viajes; en particular, esta investigación indaga en cómo lo que en un principio pueden ser consideradas opiniones - esto es, actos de habla asertivos- en realidad pueden llegar a convertirse en actos de habla directivos.

En suma, resultan necesarios más estudios que aporten información sobre los actos de habla - tanto de manera general como de una tipología concreta- utilizados en los intercambios comunicativos desde el perfil cuantitativo y el cualitativo, no solo en contextos de discurso mediado por ordenador, sino en otros géneros; o incluso empleando como corpus textos literarios, como es el caso, por ejemplo, de Iglesias Recuero $(2010 ; 2016)$. Aparte, se pueden establecer vínculos entre los resultados extraídos en este tipo de investigaciones y la fecunda y ya consagrada línea de investigación existente en estrategias de (des)cortesía. La fusión de ambos enfoques puede solventar los déficits derivados de la interpretación del analista que apuntaban Blas Arroyo (2014) o Kaul y Cordisco (2014).

\section{Referencias bibliográficas}

Ainciburu, M. C. (2018). La clasificación de los actos de habla: de la conceptualización pragmática a la identificación automatizada. En A. L. Duffé (Ed.), Singularidad y novedad en los estudios sobre los actos de habla (pp. 21-51). Síntesis.

Austin, J. (1962). How to do things with words. Harvard University Press.

Berlanga, I. y Martínez, E. (2010). Ciberlenguaje y principios de la retórica clásica. Redes sociales: el caso de Facebook. Revista Venezolana de Información, Tecnología y Conocimiento, 7(2), 47-61. https://dialnet.unirioja.es/descarga/ articulo/3294536.pdf 
Blanco Rodríguez, M. J. (2002). El chat: la conversación escrita. Estudios de Lingüística, (16), 1-90. https://rua.ua.es/dspace/bitstream/10045/6201/1/EL_16_02.pdf

Blas Arroyo, J. L. (2014). Factores condicionantes en la producción y recepción de la descortesía en un reality show. Revista de Filología de La Universidad de La Laguna, (32), 17-43.

Calvo, J. (1994). Introducción a la pragmática del español. Cátedra.

Crystal, D. (2001). Language and the Internet. Cambridge University Press.

Cuamba Herrejón, J. C. (2014). La apropiación habermasiana y deleuzeana de la teoría de los actos de habla de Austin y Searle. Devenires, (15), 83-103.

Díaz Pérez, J. C. (2012). Pragmalingüística del disfemismo y la descortesía. Los actos de habla hostiles en los medios de comunicación virtual [Tesis doctoral]. Universidad Carlos III.

Escandell, M. V. (2006). Introducción a la pragmática. Ariel. Publicado originalmente en 1996.

Fuentes, C. (2009). Descortesía y agresividad bajo el anonimato: internet. En C. Fuentes y E. Alcaide (Eds.), Manifestaciones textuales de la descortesía y agresividad verbal en diversos ámbitos comunicativos (pp. 188-210). Universidad Internacional de Andalucía.

Galán, C. y Garlito, L. (2019). La REDvolución social. En S. Robles y A. Moreno-Ortiz (Eds.), Comunicación mediada por ordenador: la lengua, el discurso y la imagen (pp. 15-37). Cátedra.

García Gabaldón, J. (2003). La configuración lingüística, comunicativa y tecnológica de los correos electrónicos. Linguax. Revista de Lenguas Aplicadas, (1), 3-17. https://revistas.uax.es/index. php/linguax/article/view/478

Garrido Medina, J. (1999). Los actos de habla: las oraciones imperativas. En V. Demonte e I. Bosque (Eds.), Gramática descriptiva de la Lengua Española. Volumen III (pp. 3879-3928). Espasa.

Giraldo, F. L. y Londoño, D. A. (2017). Descripción y referencia: el lenguaje como posibilidad de veracidad. Un asunto de límites de sistemas-mundo y actos de habla. Cuadernos de Lingüística Hispánica, (29), 163-178. https://doi. org/10.19053/0121053x.n29.2017.5858

Hernández Toribio, M. I. y Mariottini, L. (2016). TripAdvisor y actos de habla. Delimitaciones teóricas y propuestas metodológicas 
para el análisis de las estrategias de atenuación en actos de habla directivos. Pragmática Sociocultural, 4(2), 149-181. https://doi.org/10.1515/soprag-2016-0015

Iglesias Recuero, S. (2010). Aportación a la historia de la (des)cortesía: las peticiones en el siglo XVI. En F. Orletti y L. Mariottini (Eds.),(Des)cortesía en español: espacios teóricos y metodológicos para su estudio. Actas del IV Congreso Internacional del Programa EDICE (pp. 369-396). Università degli Studi Roma Trè-EDICE-Universidad de Estocolmo.

Iglesias Recuero, S. (2016). Otra cara de la pragmática histórica: la historia de los actos de habla en español: peticiones y órdenes en las Novelas Ejemplares de Miguel de Cervantes. En A. López Serena, A. Narbona y S. del Rey Quesada (Eds.), El español a través del tiempo: estudios ofrecidos a Rafael Cano Aguilar (pp. 971-994). Universidad de Sevilla.

Kaul, S. y Cordisco, A. (2014). La descortesía verbal en el contexto político-ideológico de las redes sociales. Revista de Filología de la Universidad de La Laguna, (32), 145-161. http://riull.ull. es/xmlui/handle/915/4645

Kaul, S. (2017). Tipos de descortesía verbal y emociones en contextos de cultura hispanohablante. Pragmática Sociocultural, 5(1), 1-23. https://doi.org/10.1515/soprag-2017-0001

López Alonso, C. (2006). El correo electrónico. Estudios de Lingüística del Español, (24). http://elies.rediris.es/elies24/lopezalonso. $\mathrm{htm}$

Maíz Arévalo, C. y García-Gómez, A. (2013). "You look terrific!" Social evaluation and relationships in online compliments. Discourse Studies, 15(6), 735-760. https://doi. org/10.1177/1461445613490011

Maíz Arévalo, C. (2013). "Just click 'like": Computer mediated responses to Spanish compliments. Journal of Pragmatics, (51), 4767. https://doi.org/10.1016/j.pragma.2013.03.003

Mak, B. y Chui, H. (2014). Impoliteness in Facebook status updates: Strategic talk among colleagues "outside" the workplace. Text \& Talk, 34(2), 165-185. https://doi.org/10.1515/text2013-0042

Malamuth, N., Linz, D., y Weber, R. (2005). The Internet and aggression: Motivation, disinhibitory and opportunity aspects. En Y. Amichai-Hamburger (Ed.), The social net: Understanding 
human behavior in cyberspace (pp. 163-190). Oxford University Press.

Mancera, A. y Pano, A. (2013). El discurso político en Twitter. Análisis de mensajes que "trinan". Anthropos.

Mancera, A. y Pano, A. (2014). Las redes sociales como corpus de estudio para el análisis del discurso mediado por ordenador. En S. López Poza y N. Pena Sueiro (Eds.), Humanidades digitales: desafios, logros y perspectivas de futuro (pp. 305-315). Janus, Anexo 1. http://www.janusdigital.es/anexos/contribucion.htm?id=28

Mayans i Planells, J. (2000). El lenguaje de los chats. Entre la diversión y la subversión. Revista iWorld, (29), 42-50.

Pano, A. y Moya, P. (2016). Una aproximación a los estudios sobre el discurso mediado por ordenador en lengua española. $T o$ nos Digital, 30, 1-30. https://digitum.um.es/xmlui/handle/10201/47991

Pano, A. (2008). Dialogar en la red. La lengua española en chats, emails, foros y blogs. Peter Lang.

Penas, M. A. (2018). El cibertexto y el ciberlenguaje. Síntesis.

Pérez García, E. (2014). Deixis social y (des)cortesía verbal como estrategias argumentativas. Análisis discursivo del debate político desde un enfoque sociopragmático [Tesis doctoral]. Universidad de Murcia. http://www.tdx.cat/bitstream/handle/10803/284778/TEPG.pdf?sequence $=1$

Placencia, M. E. y Bravo, D. (2002). Panorámica sobre el estudio de los actos de habla y la cortesía lingüística. En M. E. Placencia y D. Bravo (Eds.), Actos de habla y cortesía en español (pp. 1-19). Lincom Europa.

Real Academia Española, RAE-Asociación de Academias de la Lengua Española, ASALE (2009). Nueva Gramática de la Lengua Española. Madrid: Espasa.

Rocha Silva, M. A. (2004). El lenguaje de los jóvenes en el chat. Estudios sobre las Culturas Contemporáneas, 10(19), 109-140. http:// www.redalyc.org/articulo.oa?id=31601907

Sanmartín, J. (2007). El chat. La conversación tecnológica. Arco/Libros.

Searle, J. (1969). Speech acts: an essay on the philosophy of language. Cambridge University Press. 
Searle, J. (1975). Indirect speech acts. En P. Cole y J. Morgan (Eds.), Syntax and semantics. Volume 3 (pp. 59-82). Academic Press.

Theodoropoulou, I. (2015). Politeness on Facebook: The case of Greek birthday wishes. Pragmatics, 25(1), 23-45. https://doi. org/10.1075/prag.25.1.02the

Verschueren, J. (2002). Para entender la pragmática. Gredos.

Vivas, J. y Ridao, S. (2015). “iLo siento, pero me parecen horribles!!!”: análisis pragmalingüístico de la descortesía en la red social Facebook. Revista de Filología de la Universidad de La Laguna, (33), 217-236. https://dialnet.unirioja.es/descarga/ articulo/5120315.pdf

Vivas, J. (2014). La cortesía valorizadora en las redes sociales. Análisis de un corpus de publicaciones en Facebook. Pragmalingüistica, (22), 154-172. https://doi.org/10.25267/pragmalinguistica.2014.i22.09

Vivas, J. (2016). Imagen y (des)cortesía en las redes sociales en español. Un enfoque pragmático [Tesis doctoral]. Universidad de Almería, España.

Yus, F. (2010). Ciberpragmática 2.0. Nuevos usos del lenguaje en internet. Ariel. 